\title{
A Three-Component Hybrid Templated by Asymmetric Viologen Exhibiting Visible-Light-Driven Photocatalytic Degradation on Dye Pollutant in Maritime Accident Seawater
}

\author{
Xueqiang Zhuang ${ }^{1,2}$, Qiqi Wu ${ }^{3}$, Xihe Huang ${ }^{3}$, Haohong $\mathrm{Li}^{3}$, Tianjin Lin ${ }^{1,2}$ and Yali Gao ${ }^{1,2, *}$ \\ 1 School of Marine Engineering, Jimei University, Xiamen 361021, China; xqz@jmu.edu.cn (X.Z.); \\ lintianjin0592@jmu.edu.cn (T.L.) \\ 2 Fujian Province Key Laboratory of Ship and Ocean Engineering, Xiamen 361021, China \\ 3 College of Chemistry, Fuzhou University, Fuzhou 350116, China; wqq5490@163.com (Q.W.); \\ xhhuang@fzu.edu.cn (X.H.); lihh@fzu.edu.cn (H.L.) \\ * Correspondence: yali_gao@jmu.edu.cn; Tel.: +86-0592-618-5198
}

\section{check for} updates

Citation: Zhuang, X.; Wu, Q.; Huang, X.; Li, H.; Lin, T.; Gao, Y. A

Three-Component Hybrid Templated by Asymmetric Viologen Exhibiting Visible-Light-Driven Photocatalytic Degradation on Dye Pollutant in Maritime Accident Seawater.

Catalysts 2021, 11, 640.

https://doi.org/10.3390/

catal11050640

Academic Editor: Vincenzo Vaiano

Received: 27 April 2021

Accepted: 13 May 2021

Published: 18 May 2021

Publisher's Note: MDPI stays neutral with regard to jurisdictional claims in published maps and institutional affiliations.

Copyright: (c) 2021 by the authors. Licensee MDPI, Basel, Switzerland. This article is an open access article distributed under the terms and conditions of the Creative Commons Attribution (CC BY) license (https:// creativecommons.org/licenses/by/ $4.0 /)$.

\begin{abstract}
The increasing dangerous chemical pollutants led by shipping accidents call for the new pollutant treatment strategy. In this work, a new three-component hybrid $\left\{\left[\left(\mathrm{BiI}_{6}\right) \mathrm{I}_{13}\right] \cdot 2 \mathrm{I}_{3} \cdot(\mathrm{H}-\mathrm{BPA})_{4}\right\}_{\mathrm{n}}$ (1) can be used in dye degradation in seawater. The highly interesting feature of $\mathbf{1}$ lies in its unique 1-D Z-shape $\left[\left(\mathrm{BiI}_{6}\right) \mathrm{I}_{13}\right]_{\mathrm{n}}{ }^{6-}$ infinite chain constructed from the $\mathrm{I} \cdots \mathrm{I}$ contacts between mono-nuclear $\left(\mathrm{BiI}_{6}\right)^{3-}$ anions and $\mathrm{I}_{13}{ }^{3-}$ polyiodide anions. Finally, the hydrogen bonds between $\left[\left(\mathrm{BiI}_{6}\right) \mathrm{I}_{13}\right]_{n}{ }^{6-}$ polyanions and ${\mathrm{H}-\mathrm{BPA}^{2+}}^{2+}$ cations contribute to the formation a quasi-3-D network. Specifically, 1 exhibits the wide absorption zone from ultraviolet to visible regions and high charge-separation efficiency, hinting its application in visible-light catalysis. As expected, $\mathbf{1}$ represents photocatalytic activity for the degradation of rhodamine B in seawater with degradation ratio of $90 \%$, and the photocatalytic performance is stable. This work might provide new photocatalytic material for pollutant treatment in shipping accidents.
\end{abstract}

Keywords: organic-inorganic hybrid; iodobismuthate; asymmetric viologen; photocatalytic degradation; photocurrent response

\section{Introduction}

With the rapid development of the global economy, dangerous chemicals have become an important part in sea transportation, which increases sea safety uncertainty because of shipping accidents [1]. In the last decade, the increasing dangerous chemical pollutants led by shipping accidents call for the new pollutant treatment strategy. Among the dangerous chemicals, organic dyes such as rhodamine types are the most commonly observed, which have been extensively used in printing, biological staining, textiles, etc. [2]. This kind of pollutant possesses chronic toxicity not only to humans but also to animals and aquatic life, which are hard to be degraded [3]. Thus far, various treatment technologies on dye pollutants in wastewater have been executed, including biological, physical, and chemical methods $[4,5]$. As a green technology, photocatalysis method is popular in the complete mineralization of organic dyes in wastewater. Researchers have already developed numerous photocatalysts, including the traditional $\mathrm{TiO}_{2}$ semiconductor materials [6], nano particles $\left(\mathrm{ZnO}, \mathrm{CdS}, \mathrm{PbMoO}_{4}\right)[7,8], \mathrm{g}-\mathrm{C}_{3} \mathrm{~N}_{4}$ or its composites [9], and inorganic/organic hybrids $[10,11]$. Among these photocatalysts, inorganic/organic hybrids are good photocatalysts because they are stable, efficient, and band-gap tunable [12,13], which can be achieved by the structural modification on their inorganic/organic moieties or their interactions. The $\mathrm{Pb}$-based hybrids have demonstrated their photocatalysis activities on organic dyes, which stem from the synergism of all moieties [13,14]. Iodobismuthate-based photocatalysts such as $\mathrm{BiOI}$ have also illustrated the visible light activities for removal of methylene blue [15-18]. However, most of the degradation reactions were applied in 
fresh water, and the studies about the removal of dye pollutants in seawater are still in its infancy, because the $\mathrm{Na}^{+}, \mathrm{Mg}^{2+}$, and $\mathrm{Ca}^{2+}$ ions in seawater will affect the degradation efficiency [19-21]. In this work, a three-component hybrid containing iodobismuthate $\left(\mathrm{BiI}_{6}\right)^{3-}$ anion, polyiodides $\left(\mathrm{I}_{3}{ }^{-}\right.$and $\left.\mathrm{I}_{13}{ }^{3-}\right)$, and asymmetric viologen cation (protonized $4,4^{\prime}$-bipyridinium-N-pentanoic acid, $\left.(\mathrm{H}-\mathrm{BPA})^{2+}\right)$, i.e., $\left\{\left[\left(\mathrm{BiI}_{6}\right) \mathrm{I}_{13}\right] \cdot 2 \mathrm{I}_{3} \cdot(\mathrm{H}-\mathrm{BPA})_{4}\right\}_{\mathrm{n}}(\mathbf{1})$ was used as photocatalyst to degrade $\mathrm{RhB}$ in seawater, because all components are photoactive [14]. Interestingly, efficient photocatalytic degradation performances on RhB have been observed and the mechanism was discussed.

\section{Results and Discussion}

\subsection{Structure Description}

The hybrid 1 crystallizes in monoclinic space group $\mathrm{P} 2_{1} / \mathrm{c}$, which is composed of a 1-D Z-shape $\left[\left(\mathrm{BiI}_{6}\right) \mathrm{I}_{13}\right]_{\mathrm{n}}{ }^{6-}$ infinite chain constructed from the $\mathrm{I} \cdots \mathrm{I}$ contacts between mono-nuclear $\left(\mathrm{BiI}_{6}\right)^{3-}$ anion, the $\mathrm{I}_{13}{ }^{3-}$ polyiodide anion, two $\mathrm{I}_{3}$ ions, and one and four protonized 4, $4^{\prime}$-bipyridinium-N-pentanoic acid $\left(\mathrm{H}_{-}-\mathrm{BPA}^{2+}\right)$. Hydrogen bonds between $\left[\left(\mathrm{BiI}_{6}\right) \mathrm{I}_{13}\right]_{\mathrm{n}}{ }^{6-}$ polyanions and $\mathrm{H}-\mathrm{BPA}^{2+}$ cations contribute to the formation a 3-D network. The $\left(\mathrm{BiI}_{6}\right)^{3-}$ anion is commonly observed in halobismuthate system [22], which is an ideal octahedron with nearly identical equator Bi-I length and linear axial I-Bi-I angle (Figure 1a, Table 1). Polyiodides display a very rich structural chemistry ranging from $\mathrm{I}_{2}{ }^{-}$to $\mathrm{I}_{29}{ }^{3-}$, whose orientation, aggregation, and dimensionality can be controlled by the counteractions [23]. Three crystallographically independent $\mathrm{I}_{3}{ }^{-}$anions can be found in the lattice, among which $\mathrm{I}(4)-\mathrm{I}(5)-\mathrm{I}(6)$ anion is $\mathrm{I}-\mathrm{I}_{2}$ adducts with un-symmetrical I-I distances (Table 1). The other two (I(7)-I(8)-I(9), I(10)-I(11)-I(10) $\left.{ }^{\mathrm{b}}\right)$ are symmetrical and can be treated as molecular triiodide [10]. A $\mathrm{I}_{2}$ molecule (I(12)-I(13)) with typical I-I length of 2.741(2) $\AA$ can be found, which interacts with adjacent $\mathrm{I}_{3}{ }^{-}$anions via short I $\cdots \mathrm{I}$ interactions (I(9)-I(12) 3.361(4) $\AA$; I(10)-I(13) 3.30(3) $\AA, \mathrm{I}(11)-\mathrm{I}(10)-\mathrm{I}(13)$ angle $\left.144.42(5)^{\circ}\right)$ to generate a Z-shape $\mathrm{I}_{13}{ }^{3-}$ polyiodide anion (Figure 1a, Table 1). Furthermore, Z-shape $\mathrm{I}_{13}{ }^{3-}$ interacts with $\left(\mathrm{BiI}_{6}\right)^{3-}$ cluster via additional secondary $\mathrm{I} \cdots \mathrm{I}$ contacts $\left(\mathrm{I}(4)-\mathrm{I}(4)^{\mathrm{a}} 3.776(3) \AA\right)$ to generate a unique $\left[\left(\mathrm{BiI}_{6}\right) \mathrm{I}_{13}\right]_{\mathrm{n}}{ }^{6-}$ 1-D infinite chain (Figure 1a). Besides, two isolated $\mathrm{I}_{3}{ }^{-}$ anions are connected into a $\mathrm{I}_{6}{ }^{2-}$ dimmer through weak $\mathrm{I} \cdots \mathrm{I}$ contact $(\mathrm{I}(3)-\mathrm{I}(7) 3.727(3) \AA ̊)$. These I...I distances are definitively shorter than the sums of the Van der Waal's radii

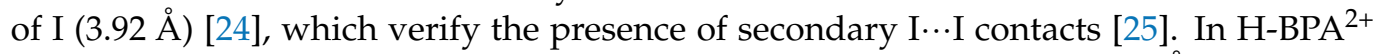
cation, the C-O bond distances in carboxyl groups $(\mathrm{C}(15)-\mathrm{O}(1)$ 1.309(18) $\AA, \mathrm{C}(15)-\mathrm{O}(2)$ 1.220(14) $\AA$; $\mathrm{C}(30)-\mathrm{O}(3) 1.303(18) \AA, \mathrm{O}(4)-\mathrm{C}(30)-\mathrm{O}(4)$ 1.240(19) $\mathrm{A})$ hint the maintenance of protons, and the protonization on $\mathrm{N}$ atoms are deduced from the charge balance. The dihedral angles between two pyridine rings in two independent $\mathrm{H}-\mathrm{BPA}^{2+}$ cations are 9.88 and $11.73^{\circ}$, suggesting a slight distortion. Two $\mathrm{H}-\mathrm{BPA}^{2+}$ cations are combined into a (H-BPA $)_{2}{ }^{4+}$ dimer via $\mathrm{O}(2)-\mathrm{H}(2 \mathrm{~W}) \cdots \mathrm{O}(3)$ hydrogen bonds, which are captured in the cavities defined by $\left[\left(\mathrm{BiI}_{6}\right) \mathrm{I}_{13}\right]_{\mathrm{n}}{ }^{6-}$ chains and $\mathrm{I}_{6}{ }^{2-}$ anions through $\mathrm{N} / \mathrm{C}-\mathrm{H} \cdots \mathrm{I}$ hydrogen bonds (Figure 1b, Table 2). Consequently, based on these I ‥I contacts and hydrogen bonds, a quasi-3-D network is generated (Figure 2).

\subsection{Absorption Spectrum and Photocurrent Response Behavior}

The purity of crystalline sample of 1 has been proved by powder X-ray diffraction (PXRD), as shown in Figure 3. The good agreement between experimental and simulated patterns indicates its good phase purities. In order to determine its photo-responsive domains, the solid-state diffuse reflectance spectrum of the newly prepared crystalline sample of $\mathbf{1}$ was conducted at room temperature (Figure 4a). Interestingly, $\mathbf{1}$ exhibits a wide absorption zone from ultraviolet to visible regions $(250-800 \mathrm{~nm}$ ), suggesting its application in visible-light catalysis. No such absorption behavior is observed for viologen compounds [26]. The presence of visible and near-infrared absorptions in this work could be attributed to charge or partial electron transfers between the $\left[\left(\mathrm{BiI}_{6}\right) \mathrm{I}_{13}\right]_{\mathrm{n}}{ }^{6-}$ anions and $\mathrm{H}-\mathrm{BPA}^{2+}$ cations induced by short contacts such as hydrogen bonding. The peaks at about 247 and $345 \mathrm{~nm}$ can be attributed to the $n / \pi-\pi^{*}$ charge transfer of H-BPA ${ }^{2+}$ cation [10], the 
broad band around $534 \mathrm{~nm}$ might relate to a mixed metal/halide-ligand charge transfer processing between the I-5p/5s to the $\pi^{*}$ orbital of $\mathrm{H}-\mathrm{BPA}^{2+}$ cations [27]. As the absorptions locate in visible regions, the photocatalytic activity was further driven by visible light.

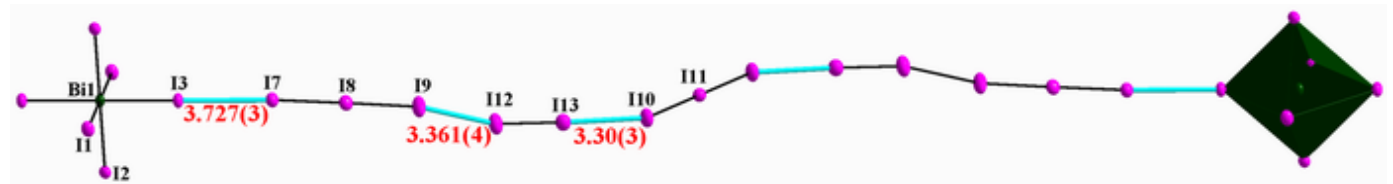

(a)

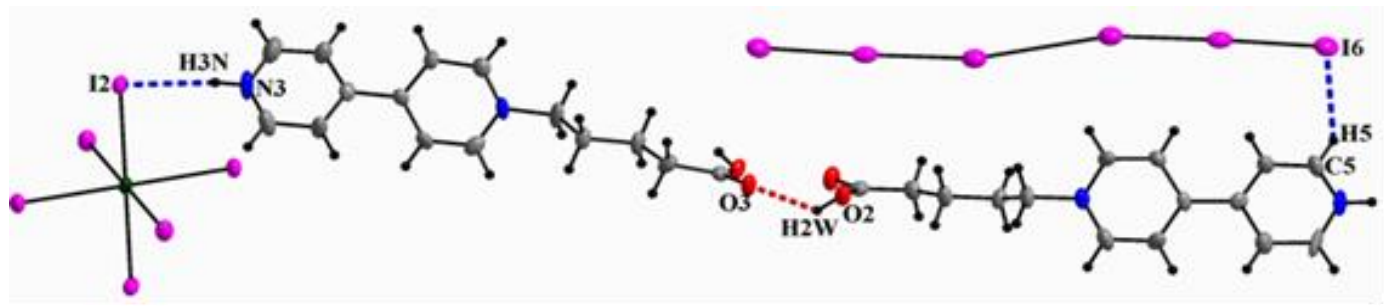

(b)

Figure 1. (a) The 1-D $\left[\left(\mathrm{BiI}_{6}\right) \mathrm{I}_{13}\right]_{\mathrm{n}}{ }^{6-}$ infinite chain constructed from the $\mathrm{I} \cdots \mathrm{I}_{\text {contacts between }}\left(\mathrm{BiI}_{6}\right)^{3-}$ ion and $\mathrm{Z}-$ shape $\mathrm{I}_{13}{ }^{3-}$ polyiodide anions; $(\mathbf{b})$ hydrogen bonds between $\left[\left(\mathrm{BiI}_{6}\right) \mathrm{I}_{13}\right]_{\mathrm{n}}{ }^{6-}$ chains, $\mathrm{I}_{6}{ }^{2-}$ anions and $\mathrm{H}-\mathrm{BPA}^{2+}$ cations.

Table 1. Selected Bond Lengths $(\AA)$ and Bond Angles $\left({ }^{\circ}\right)$.

\begin{tabular}{|c|c|c|c|c|c|}
\hline Bond & Dist. & Bond & Dist. & Dist. & Dist. \\
\hline $\operatorname{Bi}(1)-\mathrm{I}(1)$ & $3.0568(11)$ & $\operatorname{Bi}(1)-I(1)^{a}$ & $3.0568(11)$ & $\operatorname{Bi}(1)-I(2)$ & 3.1094(12) \\
\hline $\operatorname{Bi}(1)-I(2)^{a}$ & $3.1094(12)$ & $\operatorname{Bi}(1)-I(3)$ & $3.0761(10)$ & $\operatorname{Bi}(1)-\mathrm{I}(3)^{\mathrm{a}}$ & $3.0760(10)$ \\
\hline $\mathrm{I}(4)-\mathrm{I}(5)$ & $2.970(2)$ & $\mathrm{I}(5)-\mathrm{I}(6)$ & $2.888(2)$ & $\mathrm{I}(7)-\mathrm{I}(8)$ & $2.9226(17)$ \\
\hline $\mathrm{I}(8)-\mathrm{I}(9)$ & $2.9316(19)$ & $\mathrm{I}(10)-\mathrm{I}(11)$ & $2.9024(13)$ & $\mathrm{I}(9)-\mathrm{I}(12)$ & $3.361(4)$ \\
\hline $\mathrm{I}(10)-\mathrm{I}(13)$ & $3.30(3)$ & $\mathrm{I}(12)-\mathrm{I}(13)$ & $2.741(2)$ & $\mathrm{I}(3)-\mathrm{I}(7)$ & $3.727(3)$ \\
\hline Angle & $\left({ }^{\circ}\right)$ & Angle & $\left(^{\circ}\right)$ & Angle & $\left(^{\circ}\right)$ \\
\hline $\mathrm{I}(1)^{\mathrm{a}}-\mathrm{Bi}(1)-\mathrm{I}(2)^{\mathrm{a}}$ & $87.53(3)$ & $\mathrm{I}(1)-\mathrm{Bi}(1)-\mathrm{I}(2)^{\mathrm{a}}$ & $92.47(3)$ & $\mathrm{I}(3)^{\mathrm{a}}-\mathrm{Bi}(1)-\mathrm{I}(2)^{\mathrm{a}}$ & $89.43(3)$ \\
\hline $\mathrm{I}(3)-\mathrm{Bi}(1)-\mathrm{I}(2)^{\mathrm{a}}$ & $90.57(3)$ & $\mathrm{I}(1)^{\mathrm{a}}-\mathrm{Bi}(1)-\mathrm{I}(2)$ & $92.47(3)$ & $\mathrm{I}(1)-\mathrm{Bi}(1)-\mathrm{I}(2)$ & $87.53(3)$ \\
\hline $\mathrm{I}(3)^{\mathrm{a}}-\mathrm{Bi}(1)-\mathrm{I}(2)$ & $90.57(3)$ & $\mathrm{I}(3)-\mathrm{Bi}(1)-\mathrm{I}(2)$ & $89.43(3)$ & $\mathrm{I}(2)^{\mathrm{a}}-\mathrm{Bi}(1)-\mathrm{I}(2)$ & 180.0 \\
\hline $\mathrm{I}(6)-\mathrm{I}(5)-\mathrm{I}(4)$ & $176.62(6)$ & $\mathrm{I}(7)-\mathrm{I}(8)-\mathrm{I}(9)$ & $176.31(6)$ & $\mathrm{I}(10)-\mathrm{I}(11)-\mathrm{I}(10)^{\mathrm{b}}$ & $180.00(4)$ \\
\hline $\mathrm{I}(9)-\mathrm{I}(12)-\mathrm{I}(13)$ & $164.87(7)$ & $\mathrm{I}(11)-\mathrm{I}(10)-\mathrm{I}(13)$ & $144.42(5)$ & & \\
\hline
\end{tabular}

Symmetry transformation: ${ }^{\mathrm{a}}:-\mathrm{x},-\mathrm{y}+2,-\mathrm{z}+1{ }^{\mathrm{b}}:-\mathrm{x}-1,-\mathrm{y}+2,-\mathrm{z}+1$.

Table 2. Hydrogen Bond Lengths $(\AA)$ and Bond Angles $\left({ }^{\circ}\right)$.

\begin{tabular}{cccccc}
\hline D-H . . A & $\mathbf{d}(\mathbf{D}-\mathbf{H})$ & $\mathbf{d}(\mathbf{H} \ldots$ A) & $\mathbf{d}(\mathbf{D} \ldots$ A) & . DHA & Symmetry Codes \\
\hline $\mathrm{N}(1)-\mathrm{H}(1 \mathrm{~N}) \ldots \mathrm{I}(2)$ & 0.86 & 2.84 & $3.597(13)$ & 149 & $-1-\mathrm{x}, 2-\mathrm{y},-\mathrm{z}$ \\
$\mathrm{N}(3)-\mathrm{H}(3 \mathrm{~N}) \ldots \mathrm{I}(2)$ & 0.86 & 2.79 & $3.578(13)$ & 153 & $-1+\mathrm{x}, \mathrm{y},-1+\mathrm{z}$ \\
$\mathrm{C}(5)-\mathrm{H}(5) \ldots \mathrm{I}(6)$ & 0.93 & 3.04 & $3.84(2)$ & 146 & $-1-\mathrm{x}, 2-\mathrm{y},-\mathrm{z}$ \\
$\mathrm{O}(2)-\mathrm{H}(2 \mathrm{~W}) \ldots \mathrm{O}(3)$ & 0.82 & 2.10 & $2.640(14)$ & 123 & $-1-\mathrm{x}, 1 / 2+\mathrm{y}, 1 / 2-\mathrm{z}$ \\
\hline
\end{tabular}

To estimate the charge separation efficiency of $\mathbf{1}$, the crystalline sample-coated ITO electrode was prepared. A $150 \mathrm{~W}$ xenon lamp was used as light resource, and the electrode was irradiated using an $\mathrm{ON}-\mathrm{OFF}$ cycle with intervals of $20 \mathrm{~s}$, and sensitive photocurrent response can be monitored (Figure $4 \mathrm{~b}$ ). When the electrode was illuminated, repeatable and steady photocurrents with rapid response with the photocurrent density of $2.35 \mu \mathrm{A} \cdot \mathrm{cm}^{-2}$ can be achieved. This result clearly demonstrates the charges in this electrode can be separated efficiently. The good photocurrent density can be explained as the wide absorption band in visible zone or narrow optical gap [28]. 


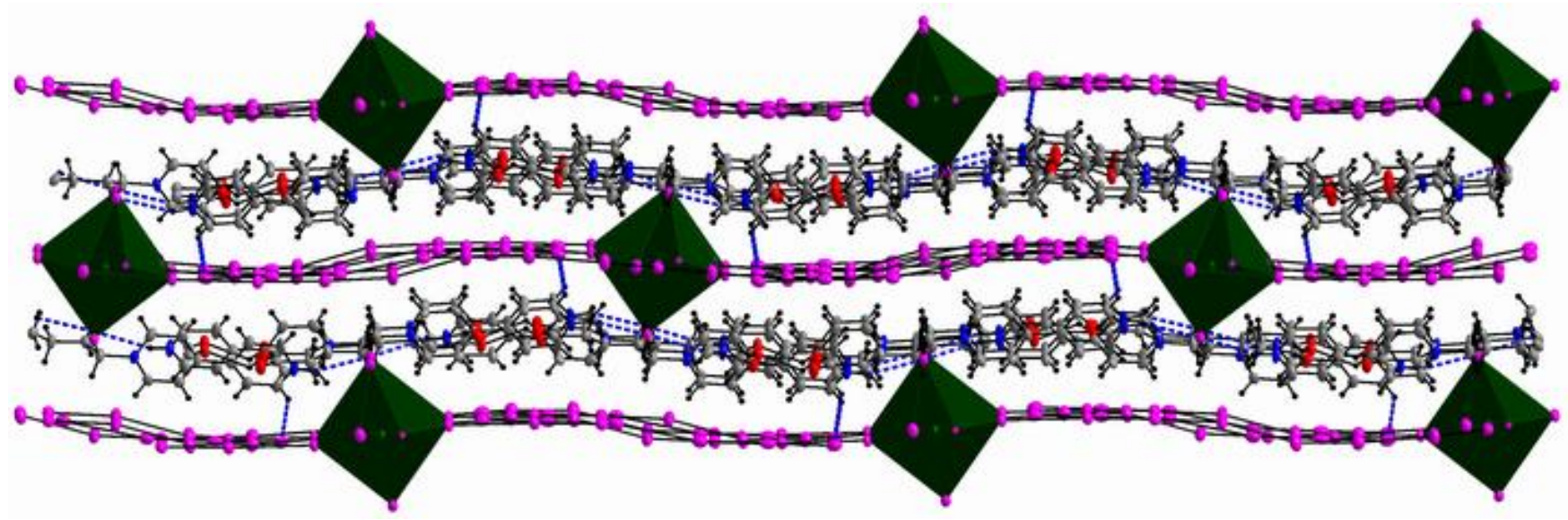

Figure 2. Quasi-3-D network of 1 based on I ‥I contacts and hydrogen bonds.

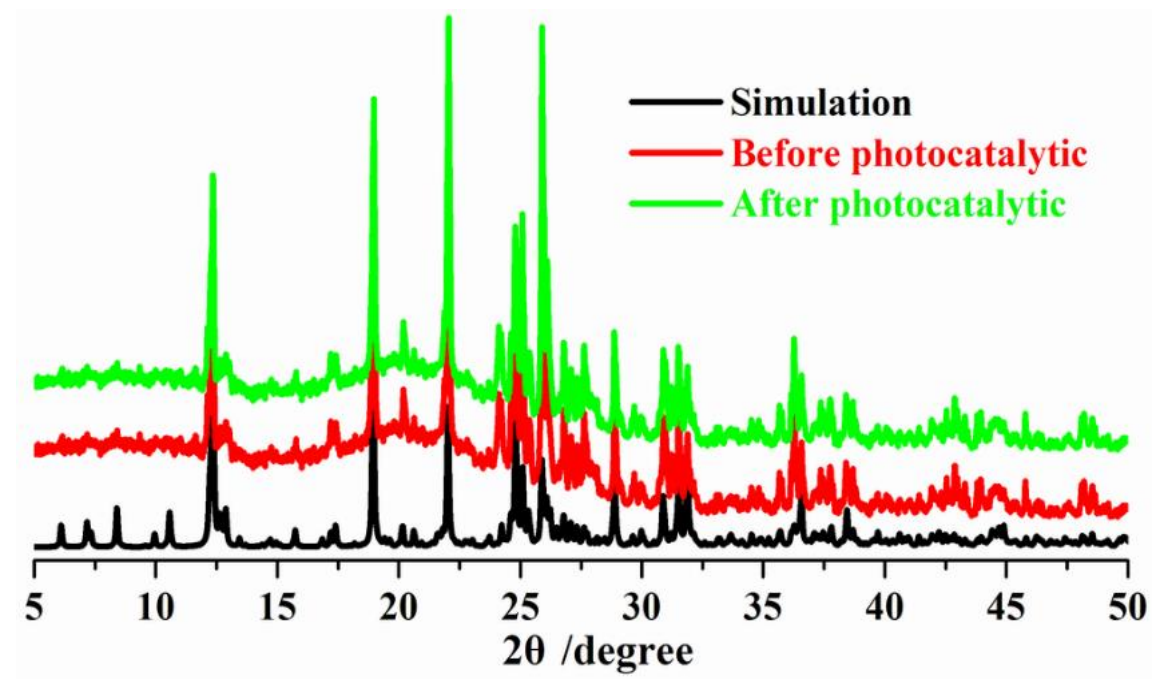

Figure 3. Powder X-ray diffraction (PXRD) patterns under different conditions for $\mathbf{1}$.

\subsection{Photocatalytic Degradation of RhB in Seawater}

The photocatalytic degradation of RhB in seawater using this three-component hybrid as catalyst was conducted. Before irradiation by visible light, the absorption-desorption equilibrium must be achieved by stirring the suspension magnetically in the dark for 30 min. As shown in Figure $5 \mathrm{a},\left\{\left[\left(\mathrm{BiI}_{6}\right) \mathrm{I}_{13}\right] \cdot 2 \mathrm{I}_{3} \cdot(\mathrm{H}-\mathrm{BPA})_{4}\right\}_{\mathrm{n}}$ exhibits a high photocatalytic performance for the degradation of RhB in seawater. The time-dependent UV-Vis spectra of RhB showing its wavelength/absorption intensity changes under the irradiation of xenon-lamp are revealed in Figure $5 \mathrm{a}$, and the concentrations of $\mathrm{RhB}(\mathrm{C})$ versus the irradiation time ( $t)$ of $\mathbf{1}$ are plotted in Figure $5 \mathrm{~b}$. As expected, with the lengthening of irradiation time, the absorption spectra of RhB decrease gradually, implying the occurrence of degradation reactions of $\mathrm{RhB}$. The degradation rates of two catalysts are $90 \%$ after the irradiation time of $120 \mathrm{~min}$. This degradation data are higher than that of $\left(\mathrm{PBPY}-\mathrm{H}_{2}\right)_{2}\left[\mathrm{PbI}_{4}\left(\mathrm{I}_{3}\right)_{2}\right][10]$. Comparably, the blank experiment without the presence of a catalyst among the same time scope shows that the photolysis rate of RhB is very low (about 5.0\%). Therefore, we can conclude that $\mathbf{1}$ is vigorous for the decomposition of $\mathrm{RhB}$ under visible light irradiation in seawater. The stability and reusability of photocatalyst was verified by recovering the sample from reaction solution after $12 \mathrm{~h}$. As the degradation reaction is heterogeneous, the catalyst can be recovered by a centrifugal method. The recovered sample was washed with ethanol and vacuum-dried at $55^{\circ} \mathrm{C}$. To our interest, the recovered amount is $38.6 \mathrm{mg}$ 
(the recovered ratio is $96.50 \%$ ). The PXRD pattern of recovered catalyst is nearly identical with that of the as-prepared sample (Figure 3), hinting that the catalyst is stable in seawater. Moreover, as seen in Figure $5 c$, the catalyst can maintain its original activity after repeating the photocatalytic degradation of $\mathrm{RhB}$ three cycles, indicating good photochemical stabilities of 1 . According to the reported literatures, the degradation process of RhB under the visible light irradiation involves $\mathrm{N}$-de-ethylation, chromophore cleavage, and mineralization, which leads to the final products of $\mathrm{CO}_{2}, \mathrm{H}_{2} \mathrm{O}, \mathrm{NO}^{3-}$, and $\mathrm{NH}^{4+}$ [29]. TOC analysis on degradation solution suggests that the removal ratio is $88.3 \%$, indicating that most of $\mathrm{RhB}$ has been degraded. However, there is only slightly TOC decrease (about $1.2 \%$ ) without irradiation of visible light.

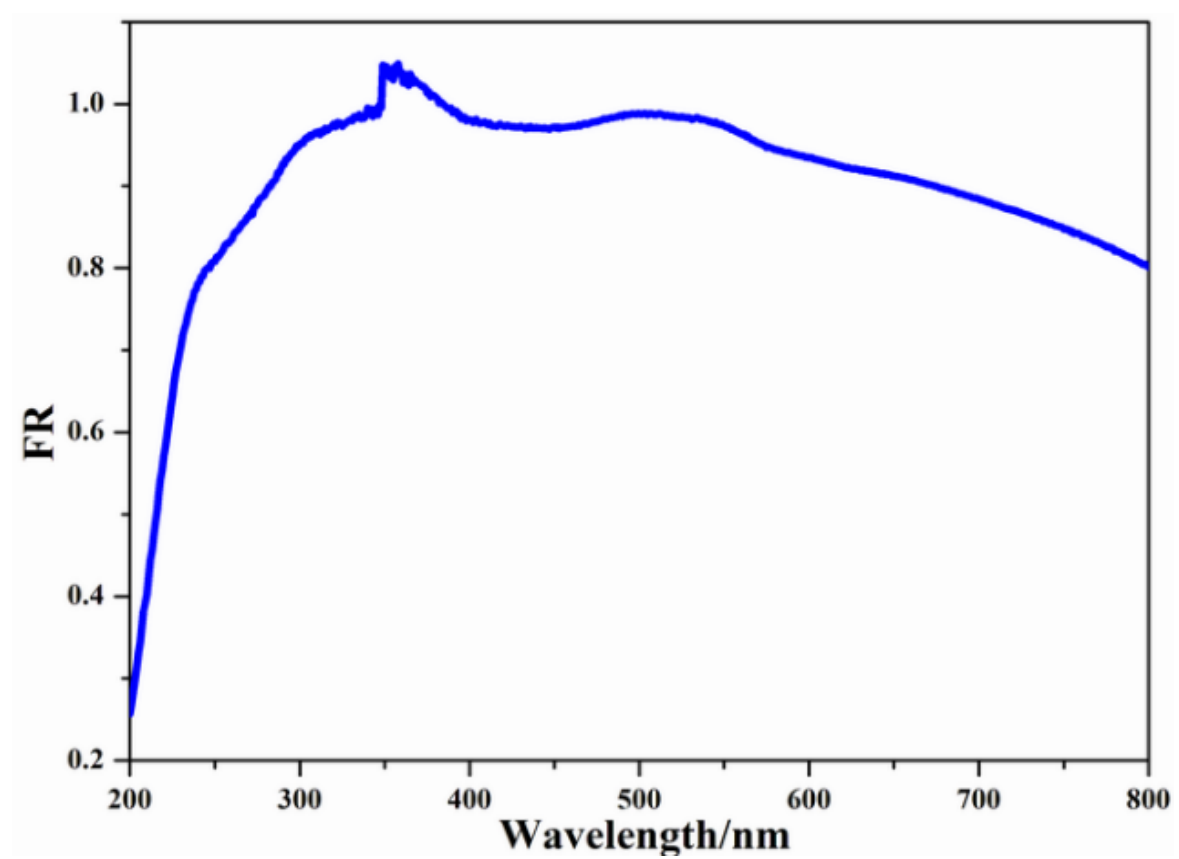

(a)

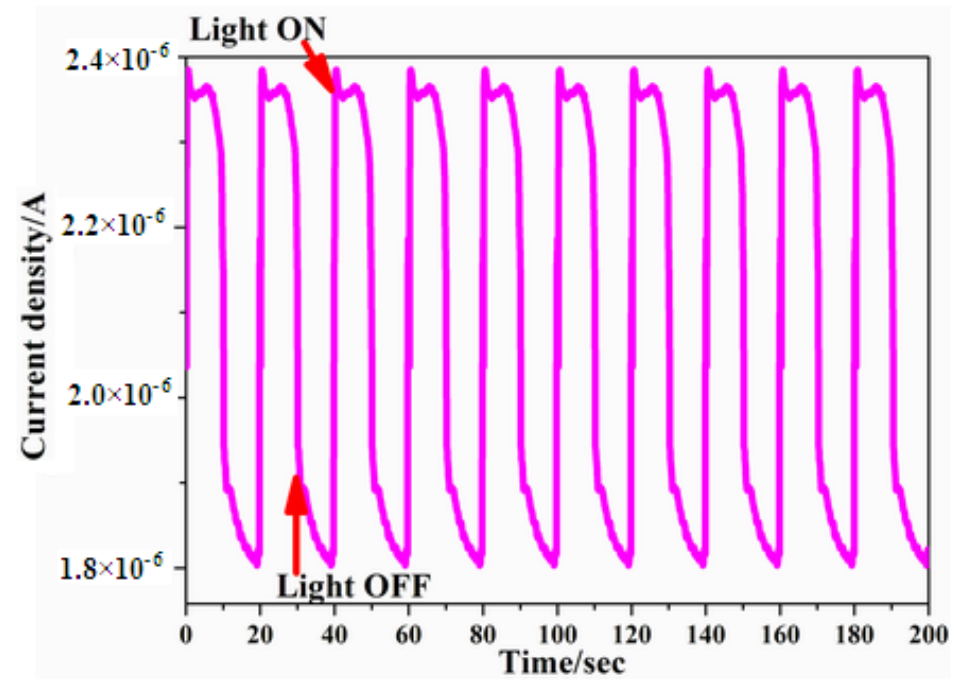

(b)

Figure 4. (a) Solid state electronic spectrum and (b) photocurrent response behavior of $\mathbf{1}$. 


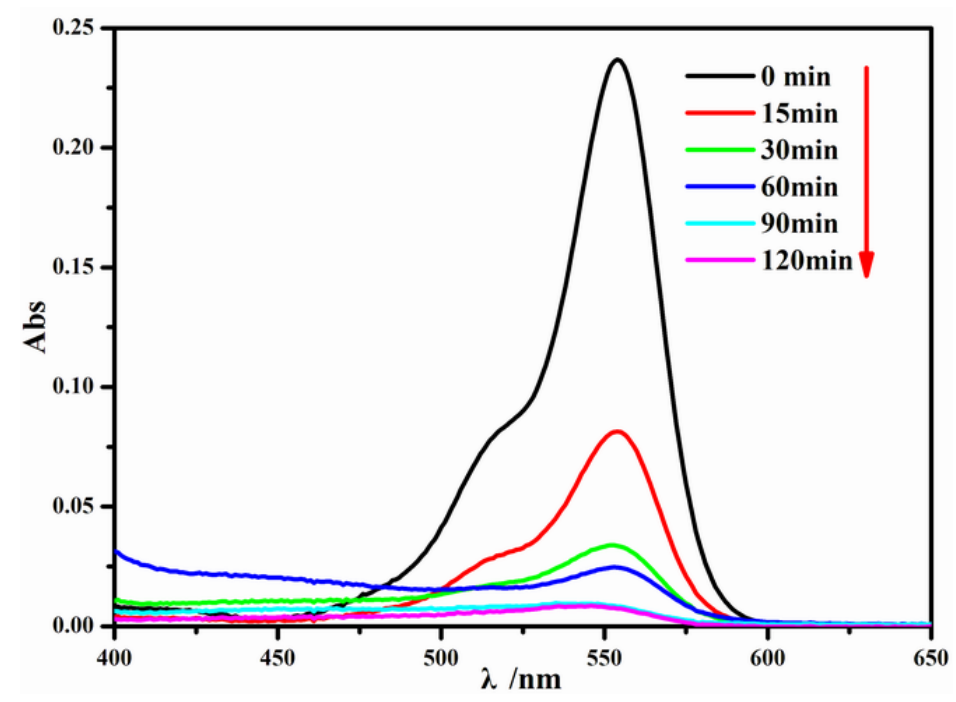

(a)

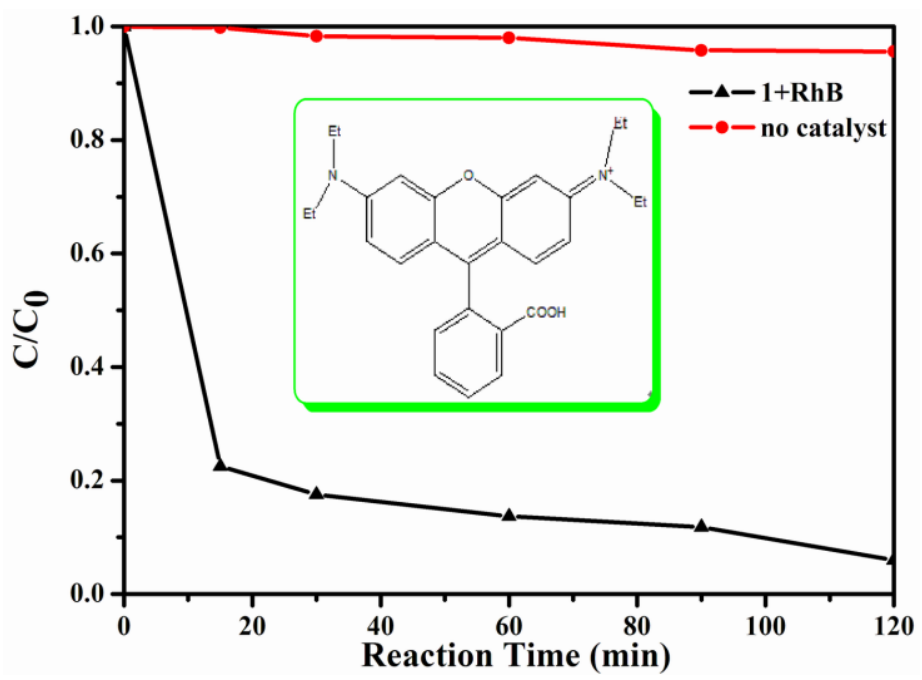

(b)

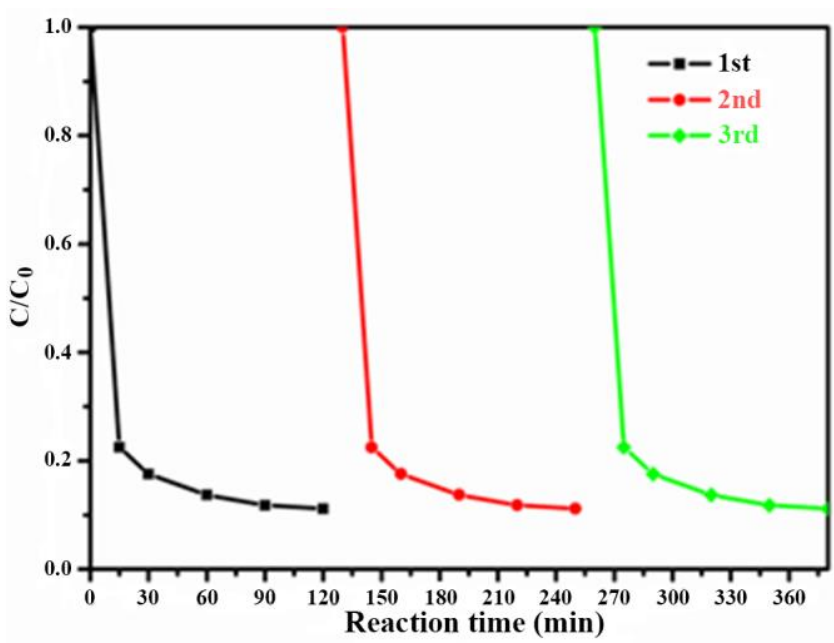

(c)

Figure 5. (a) Time-dependent UV-Vis spectra of RhB with the presence of $\mathbf{1}$ as catalyst; (b) Degradation ratio of $\mathrm{RhB}$ different irradiation time with or without the presence of catalyst; (c) Recycling tests of $\mathbf{1}$ for RhB photodegradation under light irradiation. 


\section{Experimental}

\subsection{Materials and Methods}

The chemicals including inorganic salts and organic solvents involved in the synthesis process were purchased from commercial sources with AR quality. 4,4'-bipyridinium$\mathrm{N}$-pentanoic acid (BPA·Br) was self-prepared according to literature [30]. IR spectrum was executed on a JASCO FT/IR-4100 FTIR spectrophotometer (Jasco, Easton, MD, USA) (4000-400 $\left.\mathrm{cm}^{-1}\right)$. The solid-state diffuse reflectance spectrum was measured on a UVVisible Spectrometer (Thermo SCIENTIFIC, Waltham, MA, USA, EVLUTION 220). The optical gap was evaluated from diffuse reflectance data based on Kubelka-Munk function: $\alpha / S=(1-R)^{2} /(2 R)$, in which the absorption coefficient $(\alpha)$, scattering coefficient $(S)$, and reflectance (R) are adopted [31]. Elemental analysis for $\mathrm{C}, \mathrm{H}$, and $\mathrm{N}$ was carried out on a Vario MICRO elemental analyzer (Frankfurt, Elementar, Germary). The crystalline purity of the catalyst was characterized by powder X-ray diffraction (XRD, D8-advanced, Bruker, Karlsruhe, Germany, $\mathrm{CuK} \alpha$ radiation). The photocurrent data was obtained using a CHI650 electrochemistry workstation (Shanghai, Chenghua, China) with three-electrode system. Total organic carbon (TOC) was determined on a Shimadzu TOC-L $\mathrm{L}_{\mathrm{CPH}-\mathrm{CPN}}$ equipment (Kyoto, Shimadzu, Japan).

\subsection{Synthesis}

- Synthesis of BPA·Br

BPA. Br was self-prepared based on the literature process (Scheme 1). 4,4'-bipyridine (4.7000 g, $0.03 \mathrm{~mol})$ and 5-bromo-pentanoic acid ( $3.6000 \mathrm{~g}, 0.02 \mathrm{~mol})$ were dissolved in $50 \mathrm{~mL} \mathrm{CH}_{3} \mathrm{CN}$, the mixture was heated to $40^{\circ} \mathrm{C}$ for $24 \mathrm{~h}$. Afterwards, the yellow solids can be obtained after removal of solvents by rotary evaporation. The raw product was washed with ethyl acetate four times $(25 \mathrm{~mL})$ and dried at $60{ }^{\circ} \mathrm{C}$ for $1 \mathrm{~h}(4.721 \mathrm{~g}$, yield: $70 \%)$.

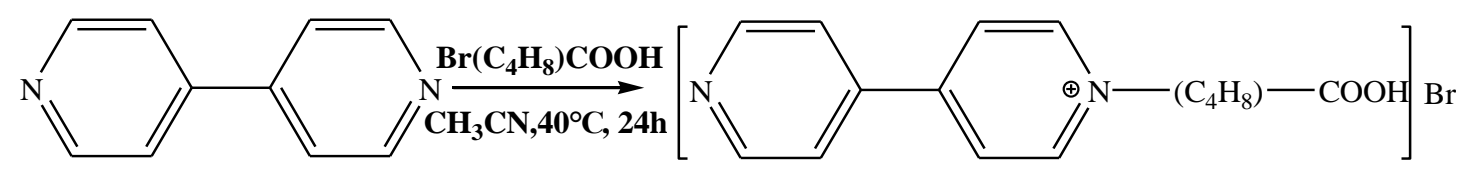

Scheme 1. Synthesis of BPA.Br.

- $\quad$ Synthesis of $\left\{\left[\left(\mathrm{BiI}_{6}\right) \mathrm{I}_{13}\right] \cdot 2 \mathrm{I}_{3} \cdot(\mathrm{H}-\mathrm{BPA})_{4}\right\}_{\mathrm{n}}(\mathbf{1})$

BPA $B r(0.1120 \mathrm{~g}, 0.33 \mathrm{mmol}), \mathrm{BiI}_{3}(0.1900 \mathrm{~g}, 0.33 \mathrm{mmol})$, and $\mathrm{I}_{2}(0.0600 \mathrm{~g}, 0.33 \mathrm{mmol})$ were dissolved in $5 \mathrm{~mL} \mathrm{HI} \mathrm{(concentration:} 50 \%$ ) and stirred magnetically for $90 \mathrm{~min}$. Then, a typical hydrothermal reaction was executed under $120^{\circ} \mathrm{C}$ for $72 \mathrm{~h}$. Finally, after cooling the autoclave to room temperature in $24 \mathrm{~h}$, black block single crystals can be separated and washed with ether $(0.2913 \mathrm{~g}$, yield $20 \%$ based on Bi.). Elemental analysis calculated for $\mathrm{C}_{60} \mathrm{H}_{72} \mathrm{BiI}_{25} \mathrm{~N}_{8} \mathrm{O}_{8}$ (4414.74): C, 16.33; $\mathrm{H}, 1.64 ; \mathrm{N}, 2.54 \%$. Found: $\mathrm{C}, 16.45 ; \mathrm{H}, 1.72 ; \mathrm{N}, 2.63 \%$. IR (KBr, $\left.\mathrm{cm}^{-1}\right)$ : 3589(w), 3036(w), 2933(w), 1703(w), 1610(m), 1580(m), 1540(m), 1416(m), 1225(m), 1062(s), 610(s), 812(s), 720(m), 500(m), 403(w).

\subsection{Photocurrent Measurements}

Solution method was adopted in the fabrication of electrode in the photocurrent measurement [32]. In detail, the newly prepared crystalline sample of $\mathbf{1}$ (5 mg) was dispersed into $0.5 \mathrm{~mL} \mathrm{DMF}$, and the resultant solution was spread on an indium tin oxide glass (ITO, $0.36 \mathrm{~cm}^{2}$ ), which was precleaned by acetone. Epoxy resin was used to cover the uncoated parts of ITO. After evaporating the solvent under an ambient atmosphere, the electrode can be obtained. A $150 \mathrm{~W}$ xenon lamp equipped with a cutoff filter $(>420 \mathrm{~nm}$ ) was used as light resource to determine its photo-responsive behavior. Photocurrent data was plotted by electrochemical workstation in a typical three-electrode system in $\mathrm{NaSO}_{4}$ aqueous solution $(0.2 \mathrm{M})$ : the 1 -coated electrode as working electrode, the platinum plate 
as counter electrode, and a $\mathrm{Ag} / \mathrm{AgCl}$ electrode as reference electrode. The lamp was turn on throughout the measurement, and the irradiation was blocked by a manual shutter at intervals of $10 \mathrm{~s}$.

\subsection{Photodegradation of $R h B$}

The photocatalytic degradation of RhB in seawater was executed under normal condition. The visible light was simulated by a A 300W xenon lamp equipped with a cutoff filter $(>420 \mathrm{~nm})$. Artificial seawater was prepared according to the literature amounts, i.e., $3.4 \mathrm{wt} \%$ containing $\mathrm{NaCl}(77.9 \%), \mathrm{MgCl}_{2}(9.6 \%), \mathrm{MgSO}_{4}(6.1 \%), \mathrm{CaSO}_{4}(4.0 \%)$, and $\mathrm{KCl}$ $(0.07 \%)$ [33]. Then, rhodamine $\mathrm{B}$ was added into seawater solution with concentration of $0.01 \mathrm{mM}$. The crystalline sample of $\mathbf{1}(40 \mathrm{mg})$ was directly scattered into the above solution $(80 \mathrm{~mL})$. Before light irradiation, the absorption equilibrium must be formed by stirring the mixture in dark for $2 \mathrm{~h}$. Afterwards the light resource was turned on. The initial concentration of $\mathrm{RhB}$ was marked as $\mathrm{C}_{0}$ at the absorption equilibrium, which was determined by the absorption band maximum in the UV-Vis spectra. Aliquots $(3 \mathrm{~mL})$ in the degradation mixture were extracted to monitor the $\mathrm{RhB}$ concentration change with intervals of $30 \mathrm{~min}$, which were labelled as $\mathrm{C}$. The percentage of degradation is reported as $\mathrm{C} / \mathrm{C}_{0}$, which is a typical method in photocatalytic degradation [34].

\subsection{X-ray Crystallography}

The single crystal structure of $\mathbf{1}$ was determined at room temperature by X-Ray diffraction method using a Bruker APEX II diffractometer equipped with graphite-monochromated MoK $\alpha$ radiation $(\lambda=0.71073 \AA)$. Afterwards, direct method and Fourier technique in the SHELXTL-97 program package were adopted to visualize its structure [35,36]. For all nonhydrogen atoms, anisotropical refinements were carried out, and hydrogen atoms attached to carbon/oxygen atoms were geometrically placed. Crystal data: monoclinic, space group $P 2{ }_{1} / \mathrm{c}$ with $\mathrm{M}_{\mathrm{r}}=4414.74, a=14.859(2), b=14.340(2), c=24.718(4) \AA, \beta=103.264(3)^{\circ}$, $V=5126.3(14) \AA^{3}, \mathrm{Z}=2, D_{\mathrm{c}}=2.857 \mathrm{~g} / \mathrm{cm}^{3}, F(000)=3920, \mu(\mathrm{MoK} \alpha)=9.293 \mathrm{~mm}^{-1}$, the final $R=0.0642$ and $\mathrm{w} R=0.1884, S=1.070,(\Delta / \sigma)_{\max }=0.000,(\Delta \rho)_{\max }=2.413$ and $(\Delta \rho)_{\min }=-2.028 \mathrm{e} / \AA^{3}$. Important bond lengths and angles are given in Table $1, \mathrm{C}-\mathrm{H} \cdots \pi$ interactions are shown in Table 2. (See the Supplementary Materials).

\section{Conclusions}

In summary, a three-component hybrid containing $\left[\left(\mathrm{BiI}_{6}\right) \mathrm{I}_{13}\right]_{\mathrm{n}}{ }^{6-}$ infinite chain, $\mathrm{I}_{3}{ }^{-}$ ions, and one and protonized 4,4'-bipyridinium-N-pentanoic acid $\left(\mathrm{H}^{-} \mathrm{BPA}^{2+}\right)$ has been synthesized and structurally determined. Specifically, its unique 1-D Z-shape $\left[\left(\mathrm{BiI}_{6}\right) \mathrm{I}_{13}\right]_{\mathrm{n}}{ }^{6-}$ chain is constructed from the $\mathrm{I} \cdots \mathrm{I}$ contacts between mono-nuclear $\left(\mathrm{BiI}_{6}\right)^{3-}$ anion and $\mathrm{I}_{13}{ }^{3-}$ polyiodide anion, and hydrogen bonds between $\left[\left(\mathrm{BiI}_{6}\right) \mathrm{I}_{13}\right]_{\mathrm{n}}{ }^{6-}$ polyanions and $\mathrm{H}-$ $\mathrm{BPA}^{2+}$ cations contribute to the formation a quasi-3-D network. The wide absorption zone from ultraviolet to visible regions $(250-800 \mathrm{~nm})$ and high charge-separation efficiency suggest its application in visible-light catalysis. As expected, $\mathbf{1}$ can be used as a good photocatalyst in the photo-degradation of rhodamine $B$ in seawater with degradation ratio of $90 \%$. This work might provide new photocatalytic material for pollutant treatment in shipping accidents.

Supplementary Materials: The following are available online at https://www.mdpi.com/article/10 .3390/catal11050640/s1, Data S1 for publication: Crystal structure data, Report S2 for review only: Crystal structure correctness report.

Author Contributions: Conceptualization, X.Z. and H.L.; methodology, Q.W. and Y.G.; data curation, Q.W. and T.L.; writing—original draft preparation, X.H.; writing—review and editing, Y.G.; funding acquisition, X.Z. All authors have read and agreed to the published version of the manuscript. 
Funding: This research was funded by the Open Fund of Fujian Province Key Laboratory of Ship and Ocean Engineering, the Natural Science Foundation of Fujian Province, China (Grant Number: 2020J05140), the Science and Technology Project of Fujian Province (Grant Number: 2019H6017), the Project of Fujian Provincial Department of Ocean and Fisheries (Grant Number: FJHJF-L-2020-6), and the Science Foundation of Jimei University, China (ZQ2020007).

Data Availability Statement: Data available on request due to restrictions, e.g., privacy or ethical.

Conflicts of Interest: The authors declare no conflict of interest.

\section{References}

1. Wang, X.P.; Shang, H.Y.; Liu, X.D.; Bai, Y.J. Fuzzy assessment methodology for emergency response capability in hazardous materials transportation. Int. J. Innov. Comput. Inf. Control 2008, 4, 2689-2696.

2. Sahoo, C.; Gupta, A.K.; Pal, A. Photocatalytic degradation of Crystal Violet (C.I. Basic Violet 3) on silver ion doped $\mathrm{TiO}_{2}$. Dyes Pigment. 2005, 66, 189-196. [CrossRef]

3. Maryanti, S.A.; Suciati, S.; Wahyuni, E.S.; Santoso, S.; Wiyasa, I.W.A. Rhodamine B triggers ovarian toxicity through oxidative stress, decreases in the number of follicles, 17B-estradiol level, and thickness of endometrium. Cukurova Med. J. 2014, 39, 451-457.

4. Feng, Y.; Zhang, Z.; Zhao, Y.; Song, L.; Wang, X.; Yang, S.; Long, Y.; Zhao, C.; Qiu, L. Accelerated rhodamine B removal by enlarged anode electric biological (EAEB) with electro-biological particle electrode (EPE) made from steel converter slag (SCS). Bioresour. Technol. 2019, 283, 1-9. [CrossRef] [PubMed]

5. Ai, X.; Zhang, P.; Dou, Y.; Wu, Y.; Pan, T.; Chu, C.; Cui, P.; Ran, J. Graphene oxide membranes with hierarchical structures used for molecule sieving. Sep. Purif. Technol. 2020, 230, 115879. [CrossRef]

6. Zhang, X.; Wang, Y.; Liu, B.; Sang, Y.; Liu, H. Heterostructures construction on $\mathrm{TiO}_{2}$ nanobelts: A powerful tool for building high-performance photocatalysts. Appl. Catal. B 2017, 202, 620-641. [CrossRef]

7. Robi, S.D.; Jian, Z.; Md, M.; Benjamin, J.C.; Yue, Z.B.; Hareem, K.; Nitu, S.; Ali, Z.; Farjana, H.; Torben, D.; et al. Two dimensional $\mathrm{PbMoO}_{4}$ : A photocatalytic material derived from a naturally non-layered crystal. Nano Energy 2018, 49, $237-246$.

8. Hadis, D.; Alireza, N. Increased photocatalytic activity of $\mathrm{NiO}$ and $\mathrm{ZnO}$ in photodegradation of a model drug aqueous solution: Effect of coupling, supporting, particles size and calcination temperature. J. Hazard. Mater. 2017, 321, 629-638.

9. Chen, X.; Chen, H.; Guan, J.; Zhen, J.; Sun, Z.; Du, P.; Lu, Y.; Yang, S. A facile mechanochemical route to a covalently bonded graphitic carbon nitride $\left(\mathrm{g}-\mathrm{C}_{3} \mathrm{~N}_{4}\right)$ and fullerene hybrid toward enhanced visible light photocatalytic hydrogen production. Nanoscale 2017, 9, 5615-5623. [CrossRef]

10. Wang, D.H.; Lin, X.Y.; Wang, Y.K.; Zhang, W.T.; Song, K.Y.; Lin, H.; Li, H.H.; Chen, Z.R. A new iodiplumbate-based hybird constructed from asymmetric viologen and polyiodides: Structure, properties and photocatalytic aactivity for the degradation of organic dye. Chin. J. Struct. Chem. 2017, 36, 2000-2006.

11. Li, J.W.; Jiang, C.C. Iodoplumbate(II)-based hybrid templated by 1,4-diazabicyclo[2.2.2]octane derivative: Structure, photocurrent response behavior and photocatalytic activity for the degradation of organic dye. Chin. J. Struct. Chem. 2018, 37, 1635-1644.

12. Li, H.H.; Zeng, X.H.; Wu, H.Y.; Jie, X.; Zheng, S.T.; Chen, Z.R. Incorporating guest molecules into honeycomb structures constructed from uranium(VI)-polycarboxylates: Structural diversities and photocatalytic activities for the degradation of organic dye. Cryst. Growth Des. 2015, 15, 10-13. [CrossRef]

13. Song, K.Y.; Zhao, L.M.; Zhang, W.T.; Li, Y.; Li, H.H.; Chen, Z.R. Two-dimensional silver-thiocyanate layers drected by viologens: Structural transformations upon low pressure stimuli, piezochromic luminescence, photocurrent responses, and photocatalytic properties. Cryst. Growth Des. 2019, 19, 177-192. [CrossRef]

14. Zhao, L.M.; Zhang, W.T.; Song, K.Y.; Wu, Q.Q.; Li, Y.; Li, H.H.; Chen, Z.R. Lead-carboxylate/polyiodide hybrids constructing from halogen bonding and asymmetric viologen: Structures, visible-light-driven photocatalytic properties and enchanced photocurrent responses. CrystEngComm 2018, 20, 2245-2252. [CrossRef]

15. Adonin, S.A.; Gorokh, I.D.; Novikov, A.S.; Samsonenko, D.G.; Yushina, I.V.; Sokolov, M.N.; Fedin, V.P. Halobismuthates with halopyridinium cations: Appearance or non-appearance of unusual colouring. CrystEngComm 2018, 20, 7766-7772. [CrossRef]

16. Adonin, S.A.; Gorokh, I.D.; Samsonenko, D.G.; Antonova, O.V.; Korolkov, I.V.; Sokolov, M.N.; Fedin, V.P. Bi(iii) polybromides: A new chapter in coordination chemistry of bismuth. Inorg. Chim. Acta 2018, 32, 5061-5063. [CrossRef]

17. VenkatRamani, S.; Schrock, R.R.; Hoveyda, A.H.; Müller, P.; Tsay, C. Synthesis of high-oxidation-State Mo-CHX complexes, where $\mathrm{X}=\mathrm{Cl}, \mathrm{CF}_{3}$, phosphonium, CN. Organometallics 2018, 37, 1641-1644. [CrossRef]

18. Moyet, M.A.; Kanan, S.M.; Varney, H.M.; Abu-Farha, N.; Gold, D.B.; Lain, W.J.; Pike, R.D.; Patterson, H.H. Synthesis and characterization of $\left(\mathrm{RPh}_{3} \mathrm{P}\right)_{3}\left[\mathrm{Bi}_{3} \mathrm{I}_{12}\right](\mathrm{R}=\mathrm{Me}, \mathrm{Ph})$ iodobismuthate complexes for photocatalyticdegradation of organic pollutants. Res. Chem. Intermed. 2019, 45, 5919-5933. [CrossRef]

19. Wang, Q.; Cai, C.; Wang, M.; Guo, Q.; Wang, B.; Luo, W.; Wang, Y.; Zhang, C.; Zhou, L.; Zhang, D.; et al. Efficient photocatalytic degradation of malachite green in seawater by the hybrid of zinc-oxide nanorods grown on three-dimensional (3D) reduced graphene oxide(RGO)/Ni foam. Materials 2018, 11, 1004. [CrossRef]

20. Chen, P.; Hu, X.; Qi, Y.; Wang, X.; Li, Z.; Zhao, L.; Liu, S.; Cui, C. Rapid degradation of azo dyes by melt-spun Mg-Zn-Ca metallic glass in artificial seawater. Metals 2017, 7, 485. [CrossRef] 
21. Makita, M.; Harata, A. Photocatalytic decolorization of rhodamine B dye as a model of dissolved organic compounds: Influence of dissolved inorganic chloride salts in seawater of the sea of Japan. Chem. Eng. Process. 2008, 47, 859-863. [CrossRef]

22. Wu, L.M.; Wu, X.T.; Chen, L. Structural overview and structure-property relationships of iodoplumbate and iodobismuthate. Coord. Chem. Rev. 2009, 253, 2787-2804. [CrossRef]

23. Garcia, M.D.; Marti-Rujas, J.; Metrangolo, P.; Peinador, C.; Pilati, T.; Resnati, G.; Terraneo, G.; Ursini, M. Dimensional caging of polyiodides: Cation-templated synthesis using bipyridinium salts. CrystEngComm 2011, 13, 4411-4416. [CrossRef]

24. Bondi, A.J. van der Waals volumes and radii. J. Phys. Chem. 1964, 68, 441-451. [CrossRef]

25. Wang, Y.K.; Wu, Y.L.; Lin, X.Y.; Wang, D.H.; Zhang, W.T.; Song, K.Y.; Li, H.H.; Chen, Z.R. Halobismuthate/diphenyliodonium

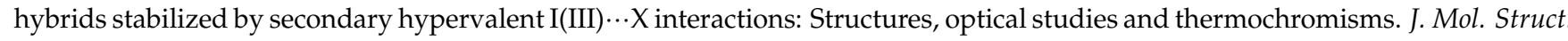
2018, 1151, 81-87. [CrossRef]

26. Tong, Z.; Pu, S.; Xiao, Q.; Liu, G.; Cui, S. Synthesis and photochromism of a novel water-soluble diarylethene with glucosyltriazolyl groups. Tetrahedron Lett. 2013, 54, 474-477. [CrossRef]

27. Patel, E.N.; Arthur, R.B.; Nicholas, A.D.; Reinheimer, E.W.; Omary, M.A.; Brichacek, M.; Patterson, H.H. Synthesis, structure and photophysical properties of a 2D network with gold dicyanide donors coordinated to aza[5]helicene viologen acceptors. Dalton Trans. 2019, 48, 10288-10297. [CrossRef] [PubMed]

28. Wang, C.; Wang, S.J.; Kong, F.G. Calixarene-protected titanium-oxo clusters and their photocurrent responses and photocatalytic performances. Inorg. Chem. 2021, 60, 5034-5041. [CrossRef]

29. Li, J.; Yang, F.; Zhou, Q.; Ren, R.; Wu, L.; Lv, Y. A regularly combined magnetic 3D hierarchical $\mathrm{Fe}_{3} \mathrm{O}_{4} / \mathrm{BiOBr}$ heterostructure: Fabrication, visible-light photocatalytic activity and degradation mechanism. J. Colloid Interface Sci. 2019, 546, 139-151. [CrossRef]

30. Zhou, X.J.; Chen, C.; Ren, C.X.; Sun, J.K.; Zhang, J. Tunable solid-state photoluminescence based on proton-triggered structural transformation of 4,4prime-bipyridinium derivative. J. Mater. Chem. C 2013, 1, 744-750. [CrossRef]

31. Wendlandt, W.M.; Hecht, H.G. Reflectance Spectroscopy; Interscience: New York, NY, USA, 1966.

32. Lin, X.Y.; Zhao, L.M.; Wang, D.H.; Wang, Y.K.; Li, M.; Li, H.H.; Chen, Z.R. Structural diversities of squarate-based complexes: Photocurrent responses and thermochromic behaviours enchanced by viologens. Inorg. Chem. Front. 2018, 5, 189-199. [CrossRef]

33. Bailey, R.A.; Clark, H.M.; Ferris, J.P.; Krause, S.; Strong, R.L. The environmental chemistry of some important elements. Chem. Environ. 2002, 347-416. [CrossRef]

34. Huang, H.W.; He, Y.; Lin, Z.S.; Kang, L.; Zhang, Y.H. Two novel Bi-Based Borate photocatalysts: Crystal structure, electronic structure, photoelectrochemical properties, and photocatalytic activity under simulated solar light irradiation. J. Phys. Chem. C 2013, 117, 22986-22994. [CrossRef]

35. Sheldrick, G.M. SHELXS-97: Program for Crystal Structure Solution; Göttingen University: Göttingen, Germany, 1997.

36. Sheldrick, G.M. SHELXL-97: Program for the Refinement of Crystal Structures; Göttingen University: Göttingen, Germany, 1997. 